OECD SERIES ON PRINCIPLES OF GOOD LABORATORY PRACTICE AND COMPLIANCE MONITORING

Number 1

OECD Principles on Good Laboratory Practice

(as revised in 1997) 
ENV/MC/CHEM(98)17 
OECD Environmental Health and Safety Publications

Series on Principles of Good Laboratory Practice

and Compliance Monitoring

No. 1

\section{OECD Principles of Good Laboratory Practice}

(as revised in 1997)

Environment Directorate

Organisation for Economic Co-operation and Development

Paris 1998 


\section{Also published in the Series on Principles of Good Laboratory Practice and Compliance Monitoring}

No. 2, Revised Guides for Compliance Monitoring Procedures for Good Laboratory Practice (1995)

No. 3, Revised Guidance for the Conduct of Laboratory Inspections and Study Audits (1995)

No. 4, Quality Assurance and GLP (1992)

No. 5, Compliance of Laboratory Suppliers with GLP Principles (1992)

No. 6, The Application of the GLP Principles to Field Studies (1992)

No. 7, The Application of the GLP Principles to Short-term Studies (1993)

No. 8, The Role and Responsibilities of the Study Director in GLP Studies (1993)

No. 9, Guidance for the Preparation of GLP Inspection Reports (1995)

No. 10, The Application of the Principles of GLP to Computerised Systems (1995)

No. 11, The Role and Responsibilities of the Sponsor in the Application of the Principles of GLP

C OECD 1998

Applications for permission to reproduce or translate all or part of this material should be made to: Head of Publications Service, OECD, 2 rue André-Pascal, 75775 Paris Cedex 16, France. 


\section{About the OECD}

The Organisation for Economic Co-operation and Development (OECD) is an intergovernmental organisation in which representatives of 29 industrialised countries in North America, Europe and the Pacific, as well as the European Commission, meet to co-ordinate and harmonize policies, discuss issues of mutual concern, and work together to respond to international problems. Most of the OECD's work is carried out by more than 200 specialised Committees and subsidiary groups composed of Member country delegates. Observers from several countries with special status at the OECD, and from interested international organisations, attend many of the OECD's Workshops and other meetings. Committees and subsidiary groups are served by the OECD Secretariat, located in Paris, France, which is organised into Directorates and Divisions.

The work of the OECD related to chemical safety is carried out in the Environmental Health and Safety Division. The Environmental Health and Safety Division publishes free-ofcharge documents in six different series: Testing and Assessment; Principles on Good Laboratory Practice and Compliance Monitoring; Pesticides; Risk Management; Chemical Accidents and Harmonization of Regulatory Oversight in Biotechnology. More information about the Environmental Health and Safety Programme and EHS publications is available on OECD's World Wide Web site (see next page).

This publication was produced within the framework of the Inter-Organization Programme for the Sound Management of Chemicals (IOMC).

The Inter-Organization Programme for the Sound Management of Chemicals (IOMC) was established in 1995 by UNEP, ILO, FAO, WHO, UNIDO and the OECD (the Participating Organizations), following recommendations made by the 1992 UN Conference on Environment and Development to strengthen co-operation and increase international coordination in the field of chemical safety. UNITAR joined the IOMC in 1997 to become the seventh Participating Organization. The purpose of the IOMC is to promote co-ordination of the policies and activities pursued by the Participating Organizations, jointly or separately, to achieve the sound management of chemicals in relation to human health and the environment. 
This publication is available electronically, at no charge.

For the complete text of this and many other Environmental Health and Safety publications, consult the OECD's

World Wide Web site (http://www.oecd.org/ehs/)

or contact:

OECD Environment Directorate, Environmental Health and Safety Division

2 rue André-Pascal

75775 Paris Cedex 16

France

Fax: (33-1) 45241675

E-mail: ehscont@oecd.org 


\section{FOREWORD}

Chemicals control legislation in OECD Member countries is founded in a proactive philosophy of preventing risk by testing and assessing chemicals to determine their potential hazards. The requirement that evaluations of chemicals be based on safety test data of sufficient quality, rigour and reproducibility is a basic principle in this legislation. The Principles of Good Laboratory Practice (GLP) have been developed to promote the quality and validity of test data used for determining the safety of chemicals and chemicals products. It is a managerial concept covering the organisational process and the conditions under which laboratory studies are planned, performed, monitored, recorded and reported. Its principles are required to be followed by test facilities carrying out studies to be submitted to national authorities for the purposes of assessment of chemicals and other uses relating to the protection of man and the environment.

The issue of data quality has an important international dimension. If regulatory authorities in countries can rely on safety test data developed abroad, duplicative testing can be avoided and costs saved to government and industry. Moreover, common principles for GLP facilitate the exchange of information and prevent the emergence of non-tariff barriers to trade, while contributing to the protection of human health and the environment.

The OECD Principles of Good Laboratory Practice were first developed by an Expert Group on GLP established in 1978 under the Special Programme on the Control of Chemicals. The GLP regulations for non-clinical laboratory studies published by the US Food and Drug Administration in 1976 provided the basis for the work of the Expert Group, which was led by the United States and comprised experts from the following countries and organisations: Australia, Austria, Belgium, Canada, Denmark, France, the Federal Republic of Germany, Greece, Italy, Japan, the Netherlands, New Zealand, Norway, Sweden, Switzerland, the United Kingdom, the United States, the Commission of the European Communities, the World Health Organisation and the International Organisation for Standardisation.

Those Principles of GLP were formally recommended for use in Member countries by the OECD Council in 1981. They were set out (in Annex II) as an integral part of the Council Decision on Mutual Acceptance of Data in the Assessment of Chemicals, which states that "data generated in the testing of chemicals in an OECD Member country in accordance with OECD Test Guidelines* and OECD Principles of Good Laboratory Practice shall be accepted in other Member countries for purposes of assessment and other uses relating to the protection of man and the environment" [C(81)30(Final)].

After a decade and half of use, Member countries considered that there was a need to review and update the Principles of GLP to account for scientific and technical progress in the field of safety testing and the fact that safety testing was currently required in many more areas than was the case at the end of the 1970's. On the proposal of the Joint Meeting of the Chemicals Group and Management Committee of the Special Programme on the Control of Chemicals, another Expert Group was therefore established in 1995 to develop a proposal to revise the Principles of GLP. The Expert Group, which completed its work in 1996, was led by Germany and comprised experts from Australia, Austria, Belgium, Canada, the Czech Republic, Denmark, Finland, France, Germany, Greece, Hungary, Ireland, Italy, Japan, Korea, the Netherlands, Norway, Poland, Portugal, the Slovak Republic, Spain, Sweden, Switzerland, the United Kingdom, the United States and the International Organisation for Standardisation.

* OECD Guidelines for the Testing of Chemicals, 1981 and continuing series. 
The Revised OECD Principles of GLP were reviewed in the relevant policy bodies of the Organisation and were adopted by Council on 26th November, 1997 [C(97)186/Final], which formally amended Annex II of the 1981 Council Decision. This publication, the first in the OECD series on Principles of Good Laboratory Practice and Compliance Monitoring, contains the Principles of GLP as revised in 1997 and, in Part Two, the three OECD Council Acts related to the Mutual Acceptance of Data.

This document cancels and replaces the Environment Monograph No. 45 entitled "The OECD Principles of Good Laboratory Practice", published in 1992 


\section{CONTENTS}

PART ONE: THE OECD PRINCIPLES OF GLP

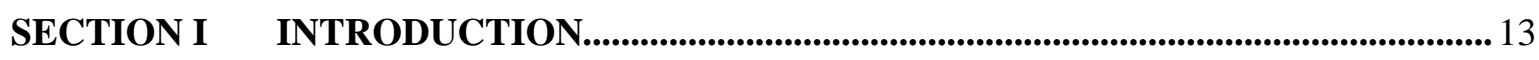

Preface

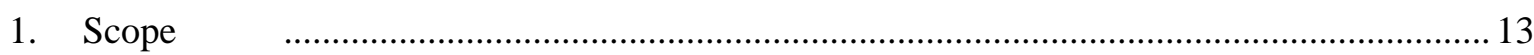

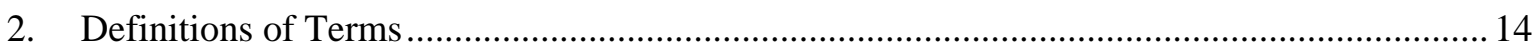

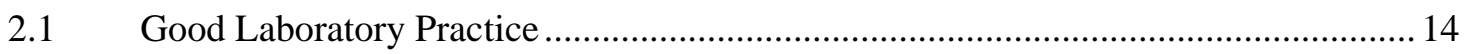

2.2 Terms Concerning the Organisation of a Test Facility ............................................... 14

2.3 Terms Concerning the Non-Clinical Health and Environmental Safety Study ........... 15

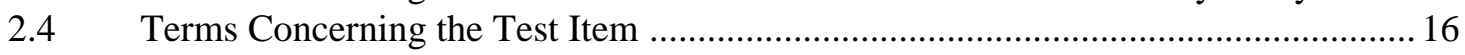

SECTION II GOOD LABORATORY PRACTICE PRINCIPLES................................... 17

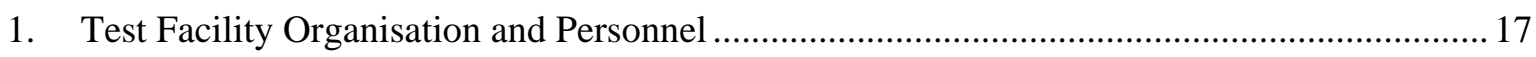

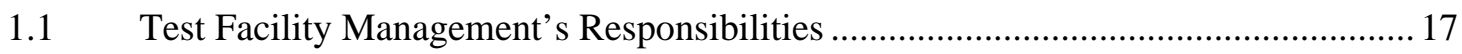

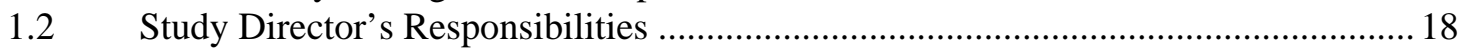

$1.3 \quad$ Principal Investigator's Responsibilities ................................................................... 19

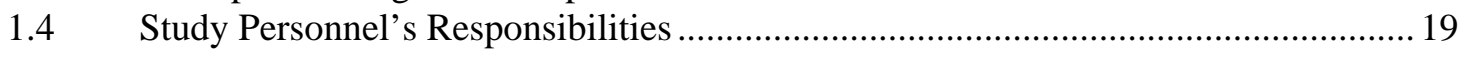

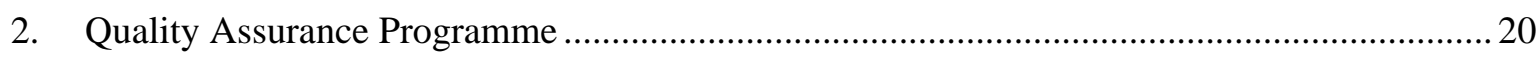

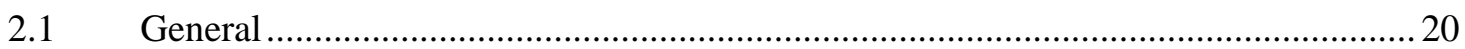

2.2 Responsibilities of the Quality Assurance Personnel ............................................... 20

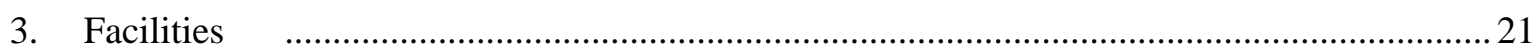

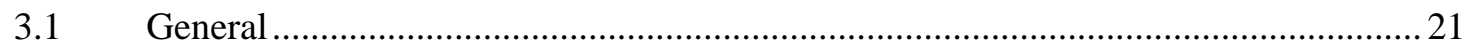

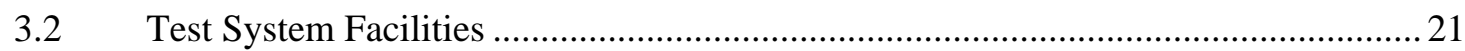

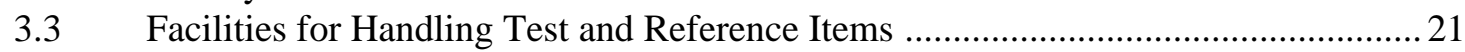

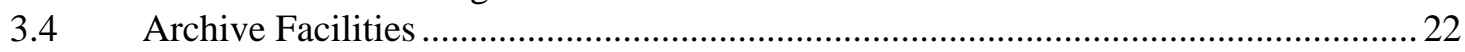

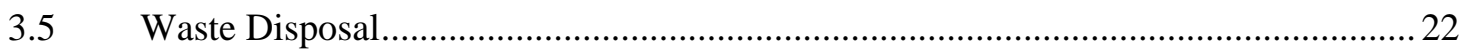

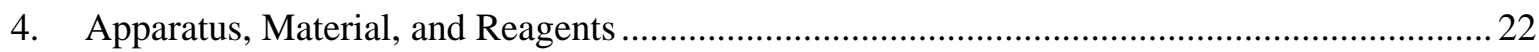




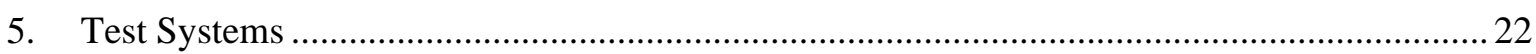

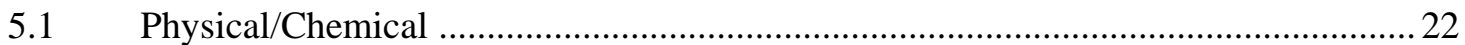

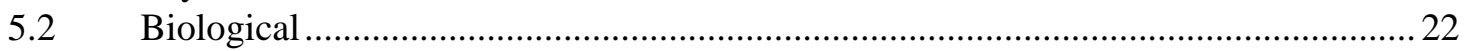

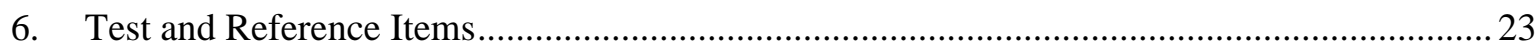

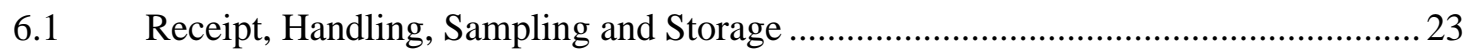

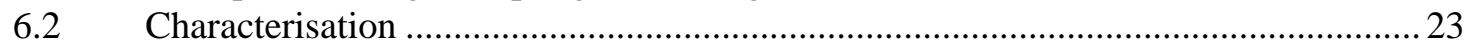

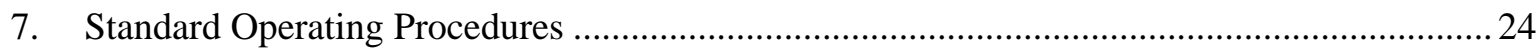

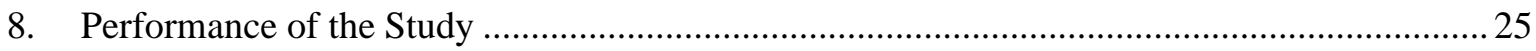

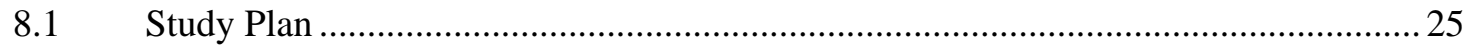

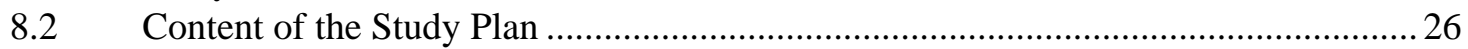

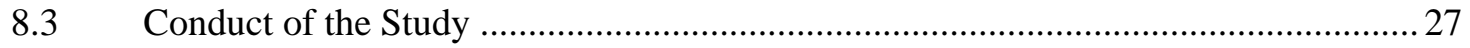

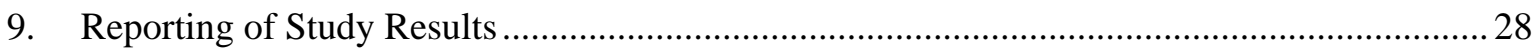

$9.1 \quad$ General

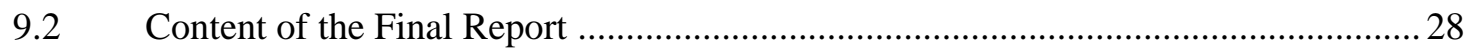

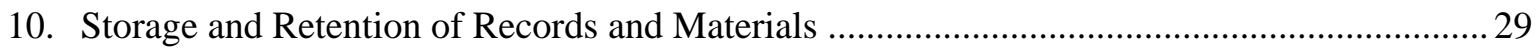

PART TWO: OECD COUNCIL ACTS RELATED TO GLP PRINCIPLES AND COMPLIANCE MONITORING

Decision of the Council concerning the Mutual Acceptance

of Data in the Assessment of Chemicals $[\mathbf{C}(\mathbf{8 1}) \mathbf{3 0}$ (Final] .....

Council Decision-Recommendation on Compliance with

Principles of Good Laboratory Practice [C(89)87(Final)]..

Council Decision on Adherence of Non-Member Countries to the

Council Acts related to the Mutual Acceptance of Data in the Assessment

of Chemicals [C(81)30(Final) and C(89)87(Final)] [C(97)114/Final] .. 


\section{PART ONE:}

\section{OECD PRINCIPLES OF GOOD LABORATORY PRACTICE*}

(as revised in 1997)

* The OECD Principles of Good Laboratory Practice are contained in Annex II of the Decision of the Council concerning the Mutual Acceptance of Data in the Assessment of Chemicals [C(81)30(Final)] (See Part Two of this document for the text of that Council Decision). The 1981 Council Decision was amended in 1997, at which time Annex II was replaced by the revised Principles of GLP [C(97)186/Final]. 
ENV/MC/CHEM(98)17 


\section{SECTION I}

\section{INTRODUCTION}

\section{Preface}

Government and industry are concerned about the quality of non-clinical health and environmental safety studies upon which hazard assessments are based. As a consequence, OECD Member countries have established criteria for the performance of these studies.

To avoid different schemes of implementation that could impede international trade in chemicals, OECD Member countries have pursued international harmonisation of test methods and good laboratory practice. In 1979 and 1980, an international group of experts established under the Special Programme on the Control of Chemicals developed the "OECD Principles of Good Laboratory Practice" (GLP), utilising common managerial and scientific practices and experience from various national and international sources. These Principles of GLP were adopted by the OECD Council in 1981, as an Annex to the Council Decision on the Mutual Acceptance of Data in the Assessment of Chemicals [C(81)30(Final)].

In 1995 and 1996, a new group of experts was formed to revise and update the Principles. The current document is the result of the consensus reached by that group. It cancels and replaces the original Principles adopted in 1981.

The purpose of these Principles of Good Laboratory Practice is to promote the development of quality test data. Comparable quality of test data forms the basis for the mutual acceptance of data among countries. If individual countries can confidently rely on test data developed in other countries, duplicative testing can be avoided, thereby saving time and resources. The application of these Principles should help to avoid the creation of technical barriers to trade, and further improve the protection of human health and the environment.

\section{Scope}

These Principles of Good Laboratory Practice should be applied to the non-clinical safety testing of test items contained in pharmaceutical products, pesticide products, cosmetic products, veterinary drugs as well as food additives, feed additives, and industrial chemicals. These test items are frequently synthetic chemicals, but may be of natural or biological origin and, in some circumstances, may be living organisms. The purpose of testing these test items is to obtain data on their properties and/or their safety with respect to human health and/or the environment.

Non-clinical health and environmental safety studies covered by the Principles of Good Laboratory Practice include work conducted in the laboratory, in greenhouses, and in the field.

Unless specifically exempted by national legislation, these Principles of Good Laboratory Practice apply to all non-clinical health and environmental safety studies required by regulations for the purpose of registering or licensing pharmaceuticals, pesticides, food and feed additives, cosmetic products, veterinary drug products and similar products, and for the regulation of industrial chemicals. 


\section{Definitions of Terms}

\subsection{Good Laboratory Practice}

1. Good Laboratory Practice (GLP) is a quality system concerned with the organisational process and the conditions under which non-clinical health and environmental safety studies are planned, performed, monitored, recorded, archived and reported.

\subsection{Terms Concerning the Organisation of a Test Facility}

1. Test facility means the persons, premises and operational unit(s) that are necessary for conducting the non-clinical health and environmental safety study. For multi-site studies, those which are conducted at more than one site, the test facility comprises the site at which the Study Director is located and all individual test sites, which individually or collectively can be considered to be test facilities.

2. Test site means the location(s) at which a phase(s) of a study is conducted.

3. Test facility management means the person(s) who has the authority and formal responsibility for the organisation and functioning of the test facility according to these Principles of Good Laboratory Practice.

4. Test site management (if appointed) means the person(s) responsible for ensuring that the phase(s) of the study, for which he is responsible, are conducted according to these Principles of Good Laboratory Practice.

5. Sponsor means an entity which commissions, supports and/or submits a non-clinical health and environmental safety study.

6. Study Director means the individual responsible for the overall conduct of the nonclinical health and environmental safety study.

7. Principal Investigator means an individual who, for a multi-site study, acts on behalf of the Study Director and has defined responsibility for delegated phases of the study. The Study Director's responsibility for the overall conduct of the study cannot be delegated to the Principal Investigator(s); this includes approval of the study plan and its amendments, approval of the final report, and ensuring that all applicable Principles of Good Laboratory Practice are followed.

8. Quality Assurance Programme means a defined system, including personnel, which is independent of study conduct and is designed to assure test facility management of compliance with these Principles of Good Laboratory Practice.

9. Standard Operating Procedures (SOPs) means documented procedures which describe how to perform tests or activities normally not specified in detail in study plans or test guidelines. 
10. Master schedule means a compilation of information to assist in the assessment of workload and for the tracking of studies at a test facility.

\subsection{Terms Concerning the Non-Clinical Health and Environmental Safety Study}

1. Non-clinical health and environmental safety study, henceforth referred to simply as "study", means an experiment or set of experiments in which a test item is examined under laboratory conditions or in the environment to obtain data on its properties and/or its safety, intended for submission to appropriate regulatory authorities.

2. Short-term study means a study of short duration with widely used, routine techniques.

3. Study plan means a document which defines the objectives and experimental design for the conduct of the study, and includes any amendments.

4. Study plan amendment means an intended change to the study plan after the study initiation date.

5. Study plan deviation means an unintended departure from the study plan after the study initiation date.

6. Test system means any biological, chemical or physical system or a combination thereof used in a study.

7. Raw data means all original test facility records and documentation, or verified copies thereof, which are the result of the original observations and activities in a study. Raw data also may include, for example, photographs, microfilm or microfiche copies, computer readable media, dictated observations, recorded data from automated instruments, or any other data storage medium that has been recognised as capable of providing secure storage of information for a time period as stated in section 10 , below.

8. Specimen means any material derived from a test system for examination, analysis, or retention.

9. Experimental starting date means the date on which the first study specific data are collected.

10. Experimental completion date means the last date on which data are collected from the study.

11. Study initiation date means the date the Study Director signs the study plan.

12. Study completion date means the date the Study Director signs the final report. 


\subsection{Terms Concerning the Test Item}

1. Test item means an article that is the subject of a study.

2. Reference item ("control item") means any article used to provide a basis for comparison with the test item.

3. Batch means a specific quantity or lot of a test item or reference item produced during a defined cycle of manufacture in such a way that it could be expected to be of a uniform character and should be designated as such.

4. Vehicle means any agent which serves as a carrier used to mix, disperse, or solubilise the test item or reference item to facilitate the administration/application to the test system. 


\section{SECTION II}

\section{GOOD LABORATORY PRACTICE PRINCIPLES}

\section{Test Facility Organisation and Personnel}

\subsection{Test Facility Management's Responsibilities}

1. Each test facility management should ensure that these Principles of Good Laboratory Practice are complied with, in its test facility.

2. At a minimum it should:

a) ensure that a statement exists which identifies the individual(s) within a test facility who fulfil the responsibilities of management as defined by these Principles of Good Laboratory Practice;

b) ensure that a sufficient number of qualified personnel, appropriate facilities, equipment, and materials are available for the timely and proper conduct of the study;

c) ensure the maintenance of a record of the qualifications, training, experience and job description for each professional and technical individual;

d) ensure that personnel clearly understand the functions they are to perform and, where necessary, provide training for these functions;

e) ensure that appropriate and technically valid Standard Operating Procedures are established and followed, and approve all original and revised Standard Operating Procedures;

f) ensure that there is a Quality Assurance Programme with designated personnel and assure that the quality assurance responsibility is being performed in accordance with these Principles of Good Laboratory Practice;

g) ensure that for each study an individual with the appropriate qualifications, training, and experience is designated by the management as the Study Director before the study is initiated. Replacement of a Study Director should be done according to established procedures, and should be documented.

h) ensure, in the event of a multi-site study, that, if needed, a Principal Investigator is designated, who is appropriately trained, qualified and experienced to supervise the delegated phase(s) of the study. Replacement of a Principal Investigator should be done according to established procedures, and should be documented.

i) ensure documented approval of the study plan by the Study Director; 
j) ensure that the Study Director has made the approved study plan available to the Quality Assurance personnel;

k) ensure the maintenance of an historical file of all Standard Operating Procedures;

1) ensure that an individual is identified as responsible for the management of the archive(s);

m) ensure the maintenance of a master schedule;

n) ensure that test facility supplies meet requirements appropriate to their use in a study;

o) ensure for a multi-site study that clear lines of communication exist between the Study Director, Principal Investigator(s), the Quality Assurance Programme(s) and study personnel;

p) ensure that test and reference items are appropriately characterised;

q) establish procedures to ensure that computerised systems are suitable for their intended purpose, and are validated, operated and maintained in accordance with these Principles of Good Laboratory Practice.

3. When a phase(s) of a study is conducted at a test site, test site management (if appointed) will have the responsibilities as defined above with the following exceptions: $1.1 .2 \mathrm{~g}$ ), i), j) and o).

\subsection{Study Director's Responsibilities}

1. The Study Director is the single point of study control and has the responsibility for the overall conduct of the study and for its final report.

2. These responsibilities should include, but not be limited to, the following functions. The Study Director should:

a) approve the study plan and any amendments to the study plan by dated signature;

b) ensure that the Quality Assurance personnel have a copy of the study plan and any amendments in a timely manner and communicate effectively with the Quality Assurance personnel as required during the conduct of the study;

c) ensure that study plans and amendments and Standard Operating Procedures are available to study personnel; 
d) ensure that the study plan and the final report for a multi-site study identify and define the role of any Principal Investigator(s) and any test facilities and test sites involved in the conduct of the study;

e) ensure that the procedures specified in the study plan are followed, and assess and document the impact of any deviations from the study plan on the quality and integrity of the study, and take appropriate corrective action if necessary; acknowledge deviations from Standard Operating Procedures during the conduct of the study;

f) ensure that all raw data generated are fully documented and recorded;

g) ensure that computerised systems used in the study have been validated;

h) sign and date the final report to indicate acceptance of responsibility for the validity of the data and to indicate the extent to which the study complies with these Principles of Good Laboratory Practice;

i) ensure that after completion (including termination) of the study, the study plan, the final report, raw data and supporting material are archived.

\subsection{Principal Investigator's Responsibilities}

The Principal Investigator will ensure that the delegated phases of the study are conducted in accordance with the applicable Principles of Good Laboratory Practice.

\subsection{Study Personnel's Responsibilities}

1. All personnel involved in the conduct of the study must be knowledgeable in those parts of the Principles of Good Laboratory Practice which are applicable to their involvement in the study.

2. Study personnel will have access to the study plan and appropriate Standard Operating Procedures applicable to their involvement in the study. It is their responsibility to comply with the instructions given in these documents. Any deviation from these instructions should be documented and communicated directly to the Study Director, and/or if appropriate, the Principal Investigator(s).

3. All study personnel are responsible for recording raw data promptly and accurately and in compliance with these Principles of Good Laboratory Practice, and are responsible for the quality of their data.

4. Study personnel should exercise health precautions to minimise risk to themselves and to ensure the integrity of the study. They should communicate to the appropriate person any relevant known health or medical condition in order that they can be excluded from operations that may affect the study. 


\section{Quality Assurance Programme}

\subsection{General}

1. The test facility should have a documented Quality Assurance Programme to assure that studies performed are in compliance with these Principles of Good Laboratory Practice.

2. The Quality Assurance Programme should be carried out by an individual or by individuals designated by and directly responsible to management and who are familiar with the test procedures.

3. This individual(s) should not be involved in the conduct of the study being assured.

\subsection{Responsibilities of the Quality Assurance Personnel}

1. The responsibilities of the Quality Assurance personnel include, but are not limited to, the following functions. They should:

a) maintain copies of all approved study plans and Standard Operating Procedures in use in the test facility and have access to an up-to-date copy of the master schedule;

b) verify that the study plan contains the information required for compliance with these Principles of Good Laboratory Practice. This verification should be documented;

c) conduct inspections to determine if all studies are conducted in accordance with these Principles of Good Laboratory Practice. Inspections should also determine that study plans and Standard Operating Procedures have been made available to study personnel and are being followed.

Inspections can be of three types as specified by Quality Assurance Programme Standard Operating Procedures:

- Study-based inspections,

- Facility-based inspections,

- Process-based inspections.

Records of such inspections should be retained.

d) inspect the final reports to confirm that the methods, procedures, and observations are accurately and completely described, and that the reported results accurately and completely reflect the raw data of the studies; 
e) promptly report any inspection results in writing to management and to the Study Director, and to the Principal Investigator(s) and the respective management, when applicable;

f) prepare and sign a statement, to be included with the final report, which specifies types of inspections and their dates, including the phase(s) of the study inspected, and the dates inspection results were reported to management and the Study Director and Principal Investigator(s), if applicable. This statement would also serve to confirm that the final report reflects the raw data.

\section{Facilities}

\subsection{General}

1. The test facility should be of suitable size, construction and location to meet the requirements of the study and to minimise disturbance that would interfere with the validity of the study.

2. The design of the test facility should provide an adequate degree of separation of the different activities to assure the proper conduct of each study.

\subsection{Test System Facilities}

1. The test facility should have a sufficient number of rooms or areas to assure the isolation of test systems and the isolation of individual projects, involving substances or organisms known to be or suspected of being biohazardous.

2. Suitable rooms or areas should be available for the diagnosis, treatment and control of diseases, in order to ensure that there is no unacceptable degree of deterioration of test systems.

3. There should be storage rooms or areas as needed for supplies and equipment. Storage rooms or areas should be separated from rooms or areas housing the test systems and should provide adequate protection against infestation, contamination, and/or deterioration.

\subsection{Facilities for Handling Test and Reference Items}

1. To prevent contamination or mix-ups, there should be separate rooms or areas for receipt and storage of the test and reference items, and mixing of the test items with a vehicle.

2. Storage rooms or areas for the test items should be separate from rooms or areas containing the test systems. They should be adequate to preserve identity, concentration, purity, and stability, and ensure safe storage for hazardous substances. 


\subsection{Archive Facilities}

Archive facilities should be provided for the secure storage and retrieval of study plans, raw data, final reports, samples of test items and specimens. Archive design and archive conditions should protect contents from untimely deterioration.

\subsection{Waste Disposal}

Handling and disposal of wastes should be carried out in such a way as not to jeopardise the integrity of studies. This includes provision for appropriate collection, storage and disposal facilities, and decontamination and transportation procedures.

\section{Apparatus, Material, and Reagents}

1. Apparatus, including validated computerised systems, used for the generation, storage and retrieval of data, and for controlling environmental factors relevant to the study should be suitably located and of appropriate design and adequate capacity.

2. Apparatus used in a study should be periodically inspected, cleaned, maintained, and calibrated according to Standard Operating Procedures. Records of these activities should be maintained. Calibration should, where appropriate, be traceable to national or international standards of measurement.

3. Apparatus and materials used in a study should not interfere adversely with the test systems.

4. Chemicals, reagents, and solutions should be labelled to indicate identity (with concentration if appropriate), expiry date and specific storage instructions. Information concerning source, preparation date and stability should be available. The expiry date may be extended on the basis of documented evaluation or analysis.

\section{Test Systems}

\subsection{Physical/Chemical}

1. Apparatus used for the generation of physical/chemical data should be suitably located and of appropriate design and adequate capacity.

2. The integrity of the physical/chemical test systems should be ensured.

\subsection{Biological}

1. Proper conditions should be established and maintained for the storage, housing, handling and care of biological test systems, in order to ensure the quality of the data. 
2. Newly received animal and plant test systems should be isolated until their health status has been evaluated. If any unusual mortality or morbidity occurs, this lot should not be used in studies and, when appropriate, should be humanely destroyed. At the experimental starting date of a study, test systems should be free of any disease or condition that might interfere with the purpose or conduct of the study. Test systems that become diseased or injured during the course of a study should be isolated and treated, if necessary to maintain the integrity of the study. Any diagnosis and treatment of any disease before or during a study should be recorded.

3. Records of source, date of arrival, and arrival condition of test systems should be maintained.

4. Biological test systems should be acclimatised to the test environment for an adequate period before the first administration/application of the test or reference item.

5. All information needed to properly identify the test systems should appear on their housing or containers. Individual test systems that are to be removed from their housing or containers during the conduct of the study should bear appropriate identification, wherever possible.

6. During use, housing or containers for test systems should be cleaned and sanitised at appropriate intervals. Any material that comes into contact with the test system should be free of contaminants at levels that would interfere with the study. Bedding for animals should be changed as required by sound husbandry practice. Use of pest control agents should be documented.

7. Test systems used in field studies should be located so as to avoid interference in the study from spray drift and from past usage of pesticides.

\section{Test and Reference Items}

\subsection{Receipt, Handling, Sampling and Storage}

1. Records including test item and reference item characterisation, date of receipt, expiry date, quantities received and used in studies should be maintained.

2. Handling, sampling, and storage procedures should be identified in order that the homogeneity and stability are assured to the degree possible and contamination or mixup are precluded.

3. Storage container(s) should carry identification information, expiry date, and specific storage instructions.

\subsection{Characterisation}

1. Each test and reference item should be appropriately identified (e.g., code, Chemical Abstracts Service Registry Number [CAS number], name, biological parameters). 
2. For each study, the identity, including batch number, purity, composition, concentrations, or other characteristics to appropriately define each batch of the test or reference items should be known.

3. In cases where the test item is supplied by the sponsor, there should be a mechanism, developed in co-operation between the sponsor and the test facility, to verify the identity of the test item subject to the study.

4. The stability of test and reference items under storage and test conditions should be known for all studies.

5. If the test item is administered or applied in a vehicle, the homogeneity, concentration and stability of the test item in that vehicle should be determined. For test items used in field studies (e.g., tank mixes), these may be determined through separate laboratory experiments.

6. A sample for analytical purposes from each batch of test item should be retained for all studies except short-term studies.

\section{Standard Operating Procedures}

7.1. A test facility should have written Standard Operating Procedures approved by test facility management that are intended to ensure the quality and integrity of the data generated by that test facility. Revisions to Standard Operating Procedures should be approved by test facility management.

7.2. Each separate test facility unit or area should have immediately available current Standard Operating Procedures relevant to the activities being performed therein. Published text books, analytical methods, articles and manuals may be used as supplements to these Standard Operating Procedures.

7.3. Deviations from Standard Operating Procedures related to the study should be documented and should be acknowledged by the Study Director and the Principal Investigator(s), as applicable.

7.4. Standard Operating Procedures should be available for, but not be limited to, the following categories of test facility activities. The details given under each heading are to be considered as illustrative examples.

\section{Test and Reference Items}

Receipt, identification, labelling, handling, sampling and storage.

\section{Apparatus, Materials and Reagents}
a) Apparatus

Use, maintenance, cleaning and calibration. 
b) Computerised Systems

Validation, operation, maintenance, security, change control and back-up.

c) Materials, Reagents and Solutions

Preparation and labelling.

3. Record Keeping, Reporting, Storage, and Retrieval

Coding of studies, data collection, preparation of reports, indexing systems, handling of data, including the use of computerised systems.

4. Test System (where appropriate)

a) Room preparation and environmental room conditions for the test system.

b) Procedures for receipt, transfer, proper placement, characterisation, identification and care of the test system.

c) Test system preparation, observations and examinations, before, during and at the conclusion of the study.

d) Handling of test system individuals found moribund or dead during the study.

e) Collection, identification and handling of specimens including necropsy and histopathology.

f) Siting and placement of test systems in test plots.

\section{Quality Assurance Procedures}

Operation of Quality Assurance personnel in planning, scheduling, performing, documenting and reporting inspections.

\section{Performance of the Study}

\subsection{Study Plan}

1. For each study, a written plan should exist prior to the initiation of the study. The study plan should be approved by dated signature of the Study Director and verified for GLP compliance by Quality Assurance personnel as specified in Section 2.2.1.b., above. The study plan should also be approved by the test facility management and the sponsor, if required by national regulation or legislation in the country where the study is being performed.

2. a) Amendments to the study plan should be justified and approved by dated signature of the Study Director and maintained with the study plan. 
b) Deviations from the study plan should be described, explained, acknowledged and dated in a timely fashion by the Study Director and/or Principal Investigator(s) and maintained with the study raw data.

3. For short-term studies, a general study plan accompanied by a study specific supplement may be used.

\subsection{Content of the Study Plan}

The study plan should contain, but not be limited to the following information:

1. Identification of the Study, the Test Item and Reference Item
a) A descriptive title;
b) A statement which reveals the nature and purpose of the study;
c) Identification of the test item by code or name (IUPAC; CAS number, biological parameters, etc.);
d) The reference item to be used.

2. Information Concerning the Sponsor and the Test Facility
a) Name and address of the sponsor;
b) Name and address of any test facilities and test sites involved;
c) Name and address of the Study Director;
d) Name and address of the Principal Investigator(s), and the phase(s) of the study delegated by the Study Director and under the responsibility of the Principal Investigator(s).

3. Dates

a) The date of approval of the study plan by signature of the Study Director. The date of approval of the study plan by signature of the test facility management and sponsor if required by national regulation or legislation in the country where the study is being performed.

b) The proposed experimental starting and completion dates.

4. Test Methods

Reference to the OECD Test Guideline or other test guideline or method to be used. 


\section{Issues (where applicable)}

a) The justification for selection of the test system;

b) Characterisation of the test system, such as the species, strain, substrain, source of supply, number, body weight range, sex, age and other pertinent information;

c) The method of administration and the reason for its choice;

d) The dose levels and/or concentration(s), frequency, and duration of administration/ application;

e) Detailed information on the experimental design, including a description of the chronological procedure of the study, all methods, materials and conditions, type and frequency of analysis, measurements, observations and examinations to be performed, and statistical methods to be used (if any).

\section{Records}

A list of records to be retained.

\subsection{Conduct of the Study}

1. A unique identification should be given to each study. All items concerning this study should carry this identification. Specimens from the study should be identified to confirm their origin. Such identification should enable traceability, as appropriate for the specimen and study.

2. The study should be conducted in accordance with the study plan.

3. All data generated during the conduct of the study should be recorded directly, promptly, accurately, and legibly by the individual entering the data. These entries should be signed or initialled and dated.

4. Any change in the raw data should be made so as not to obscure the previous entry, should indicate the reason for change and should be dated and signed or initialled by the individual making the change.

5. Data generated as a direct computer input should be identified at the time of data input by the individual(s) responsible for direct data entries. Computerised system design should always provide for the retention of full audit trails to show all changes to the data without obscuring the original data. It should be possible to associate all changes to data with the persons having made those changes, for example, by use of timed and dated (electronic) signatures. Reason for changes should be given. 


\section{Reporting of Study Results}

\subsection{General}

1. A final report should be prepared for each study. In the case of short term studies, a standardised final report accompanied by a study specific extension may be prepared.

2. Reports of Principal Investigators or scientists involved in the study should be signed and dated by them.

3. The final report should be signed and dated by the Study Director to indicate acceptance of responsibility for the validity of the data. The extent of compliance with these Principles of Good Laboratory Practice should be indicated.

4. Corrections and additions to a final report should be in the form of amendments. Amendments should clearly specify the reason for the corrections or additions and should be signed and dated by the Study Director.

5. Reformatting of the final report to comply with the submission requirements of a national registration or regulatory authority does not constitute a correction, addition or amendment to the final report.

\subsection{Content of the Final Report}

The final report should include, but not be limited to, the following information:

1. Identification of the Study, the Test Item and Reference Item
a) A descriptive title;
b) Identification of the test item by code or name (IUPAC, CAS number, biological parameters, etc.);
c) Identification of the reference item by name;
d) Characterisation of the test item including purity, stability and homogeneity.

2. Information Concerning the Sponsor and the Test Facility
a) Name and address of the sponsor;
b) Name and address of any test facilities and test sites involved;
c) Name and address of the Study Director;
d) Name and address of the Principal Investigator(s) and the phase(s) of the study delegated, if applicable;
e) Name and address of scientists having contributed reports to the final report. 


\section{Dates}

Experimental starting and completion dates.

4. Statement

A Quality Assurance Programme statement listing the types of inspections made and their dates, including the phase(s) inspected, and the dates any inspection results were reported to management and to the Study Director and Principal Investigator(s), if applicable. This statement would also serve to confirm that the final report reflects the raw data.

5. Description of Materials and Test Methods

a) Description of methods and materials used;

b) Reference to OECD Test Guideline or other test guideline or method.

6. Results

a) A summary of results;

b) All information and data required by the study plan;

c) A presentation of the results, including calculations and determinations of statistical significance;

d) An evaluation and discussion of the results and, where appropriate, conclusions.

7. Storage

The location(s) where the study plan, samples of test and reference items, specimens, raw data and the final report are to be stored.

\section{Storage and Retention of Records and Materials}

10.1 The following should be retained in the archives for the period specified by the appropriate authorities:

a) The study plan, raw data, samples of test and reference items, specimens, and the final report of each study;

b) Records of all inspections performed by the Quality Assurance Programme, as well as master schedules;

c) Records of qualifications, training, experience and job descriptions of personnel;

d) Records and reports of the maintenance and calibration of apparatus;

e) Validation documentation for computerised systems; 
f) The historical file of all Standard Operating Procedures;

g) Environmental monitoring records.

In the absence of a required retention period, the final disposition of any study materials should be documented. When samples of test and reference items and specimens are disposed of before the expiry of the required retention period for any reason, this should be justified and documented. Samples of test and reference items and specimens should be retained only as long as the quality of the preparation permits evaluation.

10.2 Material retained in the archives should be indexed so as to facilitate orderly storage and retrieval.

10.3 Only personnel authorised by management should have access to the archives. Movement of material in and out of the archives should be properly recorded.

10.4 If a test facility or an archive contracting facility goes out of business and has no legal successor, the archive should be transferred to the archives of the sponsor(s) of the study(s). 
PART TWO:

OECD COUNCIL ACTS RELATED TO GLP PRINCIPLES AND COMPLIANCE MONITORING 
ENV/MC/CHEM(98)17 


\section{DECISION OF THE COUNCIL concerning the Mutual Acceptance of Data in the Assessment of Chemicals [C(81)30(Final)]}

(Adopted by the Council at its 535th Meeting on 12th May, 1981)

The Council,

Having regard to Articles 2(a), 2(d), 3, 5(a) and 5(b) of the Convention on the Organisation for Economic Co-operation and Development of 14th December, 1960;

Having regard to the Recommendation of the Council of 26th May, 1972, on Guiding Principles concerning International Economic Aspects of Environmental Policies [C(72)128];

Having regard to the Recommendation of the Council of 14th November, 1974, on the Assessment of the Potential Environmental Effects of Chemicals [C(74)215];

Having regard to the Recommendation of the Council of 26th August, 1976, concerning Safety Controls over Cosmetics and Household Products [C(76)144(Final)];

Having regard to the Recommendation of the Council of 7th July, 1977, establishing Guidelines in respect of Procedure and Requirements for Anticipating the Effects of Chemicals on Man and in the Environment [C(77)97(Final)];

Having regard to the Decision of the Council of 21st September, 1978, concerning a Special Programme on the Control of Chemicals and the Programme of Work established therein [C(78)127(Final)];

Having regard to the Conclusions of the First High Level Meeting of the Chemicals Group of 19th May, 1980, dealing with the control of health and environmental effects of chemicals [ENV/CHEM/HLM/80.M/1];

Considering the need for concerted action amongst OECD Member countries to protect man and his environment from exposure to hazardous chemicals;

Considering the importance of international production and trade in chemicals and the mutual economic and trade advantages which accrue to OECD Member countries from harmonization of policies for chemicals control;

Considering the need to minimise the cost burden associated with testing chemicals and the need to utilise more effectively scarce test facilities and specialist manpower in Member countries;

Considering the need to encourage the generation of valid and high quality test data and noting the significant actions taken in this regard by OECD Member countries through provisional application of OECD Test Guidelines and OECD Principles of Good Laboratory Practice; 
Considering the need for and benefits of mutual acceptance in OECD countries of test data used in the assessment of chemicals and other uses relating to protection of man and the environment;

On the proposal of the High Level Meeting of the Chemicals Group, endorsed by the Environment Committee;

\section{$\underline{\text { PART I }}$}

1. DECIDES that data generated in the testing of chemicals in an OECD Member country in accordance with OECD Test Guidelines and OECD Principles of Good Laboratory Practice shall be accepted in other Member countries for purposes of assessment and other uses relating to the protection of man and the environment.

2. DECIDES that for the purposes of this decision and other Council actions the terms OECD Test Guidelines and OECD Principles of Good Laboratory Practice shall mean guidelines and principles adopted by the Council.

3. INSTRUCTS the Environment Committee to review action taken by Member countries in pursuance of this Decision and to report periodically thereon to the Council.

4. INSTRUCTS the Environment Committee to pursue a programme of work designed to facilitate implementation of this Decision with a view to establishing further agreement on assessment and control of chemicals within Member countries.

\section{$\underline{\text { PART II }}$}

To implement the Decision set forth in Part I:

1. RECOMMENDS that Member countries, in the testing of chemicals, apply the OECD Test Guidelines and the OECD Principles of Good Laboratory Practice, set forth respectively in Annexes I and $\mathrm{II}^{*}$ which are integral parts of this text.

2. INSTRUCTS the Management Committee of the Special Programme on the Control of Chemicals in conjunction with the Chemicals Group of the Environment Committee to establish an updating mechanism to ensure that the aforementioned test guidelines are modified from time to time as required through the revision of existing Guidelines or the development of new Guidelines.

3. INSTRUCTS the Management Committee of the Special Programme on the Control of Chemicals to pursue its programme of work in such a manner as to facilitate internationally-harmonized approaches to assuring compliance with the OECD Principles of Good Laboratory Practice and to report periodically thereon to the Council.

* Annex I to the Council Decision (the OECD Test Guidelines) was published separately. Annex II (the OECD Principles of Good Laboratory Practice) can be found in Part One of this publication. 


\section{COUNCIL DECISION-RECOMMENDATION on Compliance with Principles of Good Laboratory Practice [C(89)87(Final)]}

(Adopted by the Council at its 717th Meeting on 2nd October 1989)

The Council,

Having regard to Articles 5 a) and 5 b) of the Convention on the Organisation for Economic Co-operation and Development of 14th December, 1960;

Having regard to the Recommendation of the Council of 7th July, 1977 Establishing Guidelines in Respect of Procedure and Requirements for Anticipating the Effects of Chemicals on Man and in the Environment [C(77)97(Final)];

Having regard to the Decision of the Council of 12th May, 1981 concerning the Mutual Acceptance of Data in the Assessment of Chemicals [C(81)30(Final)] and, in particular, the Recommendation that Member countries, in the testing of chemicals, apply the OECD Principles of Good Laboratory Practice, set forth in Annex 2 of that Decision;

Having regard to the Recommendation of the Council of 26th July, 1983 concerning the Mutual Recognition of Compliance with Good Laboratory [C(83)95(Final)];

Having regard to the conclusions of the Third High Level Meeting of the Chemicals Group (OECD, Paris, 1988);

Considering the need to ensure that test data on chemicals provided to regulatory authorities for purposes of assessment and other uses related to the protection of human health and the environment are of high quality, valid and reliable;

Considering the need to minimise duplicative testing of chemicals, and thereby to utilise more effectively scarce test facilities and specialist manpower, and to reduce the number of animals used in testing;

Considering that recognition of procedures for monitoring compliance with good laboratory practice will facilitate mutual acceptance of data and thereby reduce duplicative testing of chemicals;

Considering that a basis for recognition of compliance monitoring procedures is an understanding of, and confidence in, the procedures in the Member country where the data are generated;

Considering that harmonized approaches to procedures for monitoring compliance with good laboratory practice would greatly facilitate the development of the necessary confidence in other countries' procedures;

On the proposal of the Joint Meeting of the Management Committee of the Special Programme on the Control of Chemicals and the Chemicals Group, endorsed by the Environment Committee; 


\section{$\underline{\text { PART I }}$}

\section{GLP Principles and Compliance Monitoring}

1. DECIDES that Member countries in which testing of chemicals for purposes of assessment related to the protection of health and the environment is being carried out pursuant to principles of good laboratory practice that are consistent with the OECD Principles of Good Laboratory Practice as set out in Annex 2 of the Council Decision [C(81)30(Final)] (hereafter called "GLP Principles") shall:

i) establish national procedures for monitoring compliance with GLP Principles, based on laboratory inspections and study audits;

ii) designate an authority or authorities to discharge the functions required by the procedures for monitoring compliance; and

iii) require that the management of test facilities issue a declaration, where applicable, that a study was carried out in accordance with GLP Principles and pursuant to any other provisions established by national legislation or administrative procedures dealing with good laboratory practice.

2. RECOMMENDS that, in developing and implementing national procedures for monitoring compliance with GLP Principles, Member countries apply the "Guides for Compliance Monitoring Procedures for Good Laboratory Practice" and the "Guidance for the Conduct of Laboratory Inspections and Study Audits," set out respectively in Annexes I and II* which are an integral part of this DecisionRecommendation.

\section{$\underline{\text { PART II }}$}

\section{Recognition of GLP Compliance among Member countries}

1. DECIDES that Member countries shall recognise the assurance by another Member country that test data have been generated in accordance with GLP Principles if such other Member country complies with Part I above and Part II paragraph 2 below.

2. DECIDES that, for purposes of the recognition of the assurance in paragraph 1 above, Member countries shall:

i) designate an authority or authorities for international liaison and for discharging other functions relevant to the recognition as set out in this Part and in the Annexes to this Decision-Recommendation;

* Annexes I and II of the Council Act as revised in 1995 can be found in Numbers 2 and 3, respectively, of this OECD series on Principles of GLP and Compliance Monitoring (Environment Monographs No. 110 and No. 111). 
ii) exchange with other Member countries relevant information concerning their procedures for monitoring compliance, in accordance with the guidance set out in Annex III * which is an integral part of this Decision-Recommendation, and

iii) implement procedures whereby, where good reason exists, information concerning GLP compliance of a test facility (including information focusing on a particular study) within their jurisdiction can be sought by another Member country.

3. DECIDES that the Council Recommendation concerning the Mutual Recognition of Compliance with Good Laboratory Practice [C(83)95(Final)] shall be repealed.

\section{PART III}

\section{Future OECD Activities}

1. INSTRUCTS the Environment Committee and the Management Committee of the Special Programme on the Control of Chemicals to ensure that the "Guides for Compliance Monitoring Procedures for Good Laboratory Practice" and the "Guidance for the Conduct of Laboratory Inspections and Study Audits" set out in Annexes I and $\mathrm{II}^{* *}$ are updated and expanded, as necessary, in light of developments and experience of Member countries and relevant work in other international organisations.

2. INSTRUCTS the Environment Committee and the Management Committee of the Special Programme on the Control of Chemicals to pursue a programme of work designed to facilitate the implementation of this Decision-Recommendation, and to ensure continuing exchange of information and experience on technical and administrative matters related to the application of GLP Principles and the implementation of procedures for monitoring compliance with good laboratory practice.

3. INSTRUCTS the Environment Committee and the Management Committee of the Special Programme on the Control of Chemicals to review actions taken by Member countries in pursuance of this Decision-Recommendation.

\footnotetext{
* Annex III of the Council Act as revised in 1995 will be found in Number 2 of this OECD series on Principles of GLP and Compliance Monitoring (Environment Monograph No. 110).

** See footnote on previous page.
} 
ENV/MC/CHEM(98)17 


\section{COUNCIL DECISION \\ concerning the Adherence of Non-member Countries to the Council Acts related to the Mutual Acceptance of Data in the Assessment of Chemicals [C(81)30(FINAL) AND C(89)87(FINAL)] [C(97)114/Final]}

(Adopted by the Council at its 912th meeting on 26th November, 1997)

The Council,

Having regard to Articles 5(a) and 5(c) of the Convention on the Organisation for Economic Co-operation and Development of 14th December, 1960;

Having regard to the Decision of the Council of 12th May, 1981, concerning the Mutual Acceptance of Data in the Assessment of Chemicals [C(81)30(Final)];

Having regard to the Decision of the Council of 26th July, 1983, concerning the Protection of Proprietary Rights to Data submitted in Notification of New Chemicals [C(83)96(Final)] and the Recommendations of the same date concerning the Exchange of Confidential Data on Chemicals [C(83)97(Final)] and the OECD List of Non-Confidential Data on Chemicals [C(83)98(Final)];

Having regard to the Decision Recommendation of the Council of 2nd October, 1989 on Compliance with Principles of Good Laboratory Practice [C(89)87(Final)] as amended];

Considering that effective implementation of the OECD Council Acts [C(81)30(Final)] and [C(89)87(Final)] is essential in view of the extension of these acts to adherence by non-member countries;

Recognising that the conclusion of agreements among Members and with non-member countries constitutes a means for effective implementation of these Council Acts;

Recognising that adherence to the OECD Council Acts does not preclude use or acceptance of test data obtained in accordance with other scientifically valid and specified test methods, as developed for specific chemical product areas;

Considering that on 14th June, 1992 the United Nations Conference on Environment and Development in Chapter 19, section E of Agenda 21, recommended that governments and international organisations should co-operate, particularly with developing countries, to develop appropriate tools for management of chemicals;

Considering the commitments made by Ministers at the meeting of the Council at Ministerial level of 23rd and 24th May, 1995 to support the integration of developing countries and economies in transition into the world economic system, and to pursue further progress toward a better environment;

Considering that Member countries and non-member countries would derive both economic and environmental benefits from enlarged participation in the OECD Council Acts related to mutual acceptance of data in the assessment of chemicals; 
Considering that non-member countries are increasingly demonstrating an interest in participating in the OECD Council Acts related to mutual acceptance of data in the assessment of chemicals;

Considering that the chemical industries in all nations have an interest in harmonized testing requirements and will benefit from the elimination of costly, duplicative testing and the avoidance of nontariff barriers to trade;

Considering that expanded international co-operation to reduce duplicative testing would, in the process, diminish the use of animals for safety testing;

Considering, therefore, that it is appropriate and timely to pursue broadened international participation in the OECD programme on mutual acceptance of data in the assessment of chemicals, specifically by opening up the relevant OECD Council Acts to adherence by non-member countries and that a clear administrative procedure is required to facilitate this process;

On the proposal of the Joint Meeting of the Chemicals Group and Management Committee of the Special Programme on the Control of Chemicals, endorsed by the Environment Policy Committee;

1. DECIDES to open the OECD Council Acts related to the mutual acceptance of data in the assessment of chemicals* to adherence by non-member countries which express their willingness and demonstrate their ability to participate therein.

2. DECIDES that non-member countries adhering to the Council Acts shall be entitled to join the part of the OECD Chemicals Programme involving the mutual acceptance of data, with the same rights and obligations as Member countries.

3. DECIDES that adherence to the Council Acts and participation in the part of the OECD Chemicals Programme related to the mutual acceptance of data shall be governed by the procedure set out in the Appendix to this Decision, of which it forms an integral part.

4. RECOMMENDS that Member countries, with a view to facilitating the extension of the Council Acts to non-member countries, take or pursue all available means to ensure the most effective implementation of the Council Acts. Pending this effective implementation of the Council Acts by nonmembers, Member countries shall be free to establish mutual acceptance of data with non-member countries on a bilateral basis.

5. INSTRUCTS the Management Committee of the Special Programme on the Control of Chemicals to assume responsibility for promoting international awareness of the Council Acts, with a view to informing, advising and otherwise encouraging non-member countries to participate in the programmes and activities that have been established by OECD countries pursuant to these Council Acts. Further, the Management Committee should monitor closely the technical aspects of implementation of the procedure set out in the Appendix, review the implementation of this Decision, and report thereon to Council within three years.

* These Council Acts are: the 1981 Council Decision concerning the Mutual Acceptance of Data in the Assessment of Chemicals [C(81)30(Final)] as amended, together with the OECD Guidelines for the Testing of Chemicals and the OECD Principles of Good Laboratory Practice, and the 1989 Council DecisionRecommendation on Compliance with Principles of Good Laboratory Practice [C(89)87(Final)] as amended and are hereafter referred to as "the Council Acts". 


\section{ANNEX \\ PROCEDURE FOR ADHERENCE OF NON-MEMBER COUNTRIES TO THE COUNCIL ACTS RELATED TO THE MUTUAL ACCEPTANCE OF DATA IN THE ASSESSMENT OF CHEMICALS}

i) The OECD Secretariat should ensure that an interested non-member country is provided with full information on the rights and obligations associated with adhering to the OECD Council Acts related to mutual acceptance of data in the assessment of chemicals.

ii) At the invitation of the Council, the interested non-member country would confirm, at an appropriate level, that it would agree to provisionally adhere to the Council Acts and to accept, for purposes of assessment and other uses relating to the protection of man and the environment, data generated in the testing of chemicals with OECD Test Guidelines and OECD Principles of Good Laboratory Practice.

iii) Following such invitation, confirmation and provisional adherence, the Joint Meeting of the Chemicals Group and Management Committee of the Special Programme on the Control of Chemicals (Joint Meeting) would organise, in consultation with the non-member country, technical support that might assist in the implementation of the Council Acts.

iv) The non-member country would be invited by the Joint Meeting to nominate a Test Guideline Co-ordinator and to take part in the activities and meetings related to the development and updating of OECD Test Guidelines and to take part in technical meetings related to GLP and, if recommended by the OECD Panel on GLP, to attend as an observer meetings of the Panel. Such an invitation would be for a maximum of three years and could be renewed by the Joint Meeting.

v) Once the non-member country has fully implemented the Council Acts, and taking account of the recommendation of the Joint Meeting in this respect, the non-member country may be invited by the Council to adhere to the Council Acts and to join the part of the OECD Chemicals Programme involving the mutual acceptance of data as a full member; this would require the non-member country to contribute to the resource costs of implementing this part of the Chemicals Programme.

vi) Participation may be terminated by either party upon one year advance notice. The Council may set any further terms and conditions to the invitation. 